\title{
Utero-cuteneous Fistula: Rare Complication of Caesarean Section
}

\section{Pant PR}

Department of Obs/Gyn, Institute of Medicine, TU Teaching Hospital, Kathmandu, Nepal

\section{DEAR EDITOR,}

Vesicovaginal and rectovaginal fistulae are common genital fistulae, whereas Utero-cutaneous fistulae are very rare. Fistulae involving the uterus are usually result of abortions, postpartum and postoperative complications. This is report of an unusual case of an utero-cutaneous fistula that developed in a multiparous 32 years old woman after second cesarean section.

A 32years old woman presented with pus like discharge coming out from the incisional scar of cesarean section which was done six months back for indication of previous cesarean with contracted pelvis. Postoperative period was uneventful for two months but after two months pus started to come out from the incision site and antibiotic treatment was ineffective. There was no fever .However the pus like discharge from the incision site was associated with similar discharge from vagina.

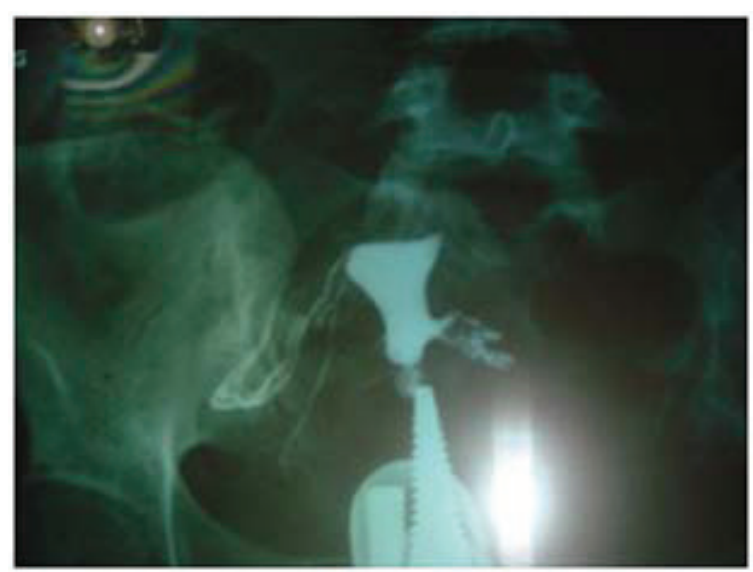

Figure 1. Hysterosalpingogram suggestive of uterocutaneous fistula.

\section{CORRESPONDENCE}

Dr. Padam Raj Pant

Department of Obstetrics and Gynaecology Institute of Medicine, TU Teaching Hospital

Kathmandu, Nepal

Phone: 9851101629

Email: padam1629@gmail.com
She underwent excision of fistula tract. Tissue was sent for histopathology which was suggestive of tuberculosis. Antituberculosis treatment was started, after which the incisional scar healed well.

A number of cases of uterocutaneous fistulae are reported in the literature. Majority of these fistulae developed following classical cesarean section. The decrease in the incidence of uterocutaneous fistula may reasonably be attributed to marked decrease in the frequency of classical cesarean section in modern obstetrics ${ }^{1}$. Most uterocutaneous fistula originate from some type of infective process that disrupts the continuity of tissues involved. Jain et al ${ }^{2}$ reported an uterocutaneous fistula following lower segment cesarean section. Gupta et al 3 reported a uterocutaneous fistula which developed following septic abortion induced by laminaria tent insertion in the cervix. Dragoumis et al ${ }^{4}$ described a case of endometriotic uterocutaneous fistula after Cesarean section.

Management of uterocutaneous fistula is sometimes difficult. Surgical excision of the fistulous tract is the treatment of choice. ${ }^{5}$ Most cases end up with hysterectomy, however Seyhan et al ${ }^{6}$ reported a case of uterocutaneous fistula that was successfully treated with gonadotropin releasing hormone agonist administration.

Post cesarean section cervicocutaneous fistula was reported by Ghose and colleagues ${ }^{7}$ in which there was no tuberculosis and there was history of menstrual blood leakage from the fistulous opening but in present case there was only pus like discharge from the fistulous opening.

In this case the cause of fistula was tuberculosis so it was difficult to treat this fistula. Diagnosis was made only after histopathology report of excised fistulous tract. 


\section{REFERENCES}

1. Desoouky DA. Uteroabdominal sinus following cesarean Section Am J Obstetric Gynecology. 1980;137(1):147-8.

2. Jain V, Jain S, Sandeep et al. Post cesarean uterocutaneous FistulaA rare clinical entity. J Obstetric Gynecology. 2003;53:97.

3. Gupta SK, Shukla VK, Verma DN et al. Uterocutaneous Fistula. Post Grad Med J. 1993;69(816):822-3.
4. Dragoumis K, Mikos T, Zafrakas M, Assimakopoulos E, Stamatopoulos P, Bontis J. Gynecology Obstetric Invest. 2004;57(2):90-2.

5. Shukla D, Pandey S, Pandey LK et al. Obstet Gynecol. 2006;108:732-

6. Seyhan A, Ata B, Sidal B, Urman B. Obstet Gynecol.2008;111(2):526-8.

7. Ghose S, Maurya DK, Gowda M, Begum P. An Unusual Case of Cervico-cutaneous Fistula. Afr J Reprod Health. 2010;14(1):135-7. 